\title{
All-Day Anti-Icing/Deicing Film Based on Combined Photo-Electro-Thermal Conversion
}

Tongtong Hao ${ }^{1,2}$, Zhicheng Zhit, Huige Yang ${ }^{1^{*}}$, Zhiyuan $\mathrm{He}^{2^{*}}$, Jianjun Wang ${ }^{2,3^{*}}$

1. School of Materials Science and Engineering, Zhengzhou University, Zhengzhou 450001, P. R. China.

2. Key Laboratory of Green Printing, Institute of Chemistry, Chinese Academy of Sciences, Beijing, 100190.

3. School of Future Technology, University of Chinese Academy of Sciences, Beijing, 100049.

4. Zhong Neng Power-Tech Development CO.,LTD. No.6-9, Fuchengmen North Street, Xicheng District, Beijing, China

*Corresponding $\quad$ author: $\quad$ yanghg@zzu.edu.can; $\quad$ hezy@iccas.ac.cn; wangj220@iccas.ac.cn 


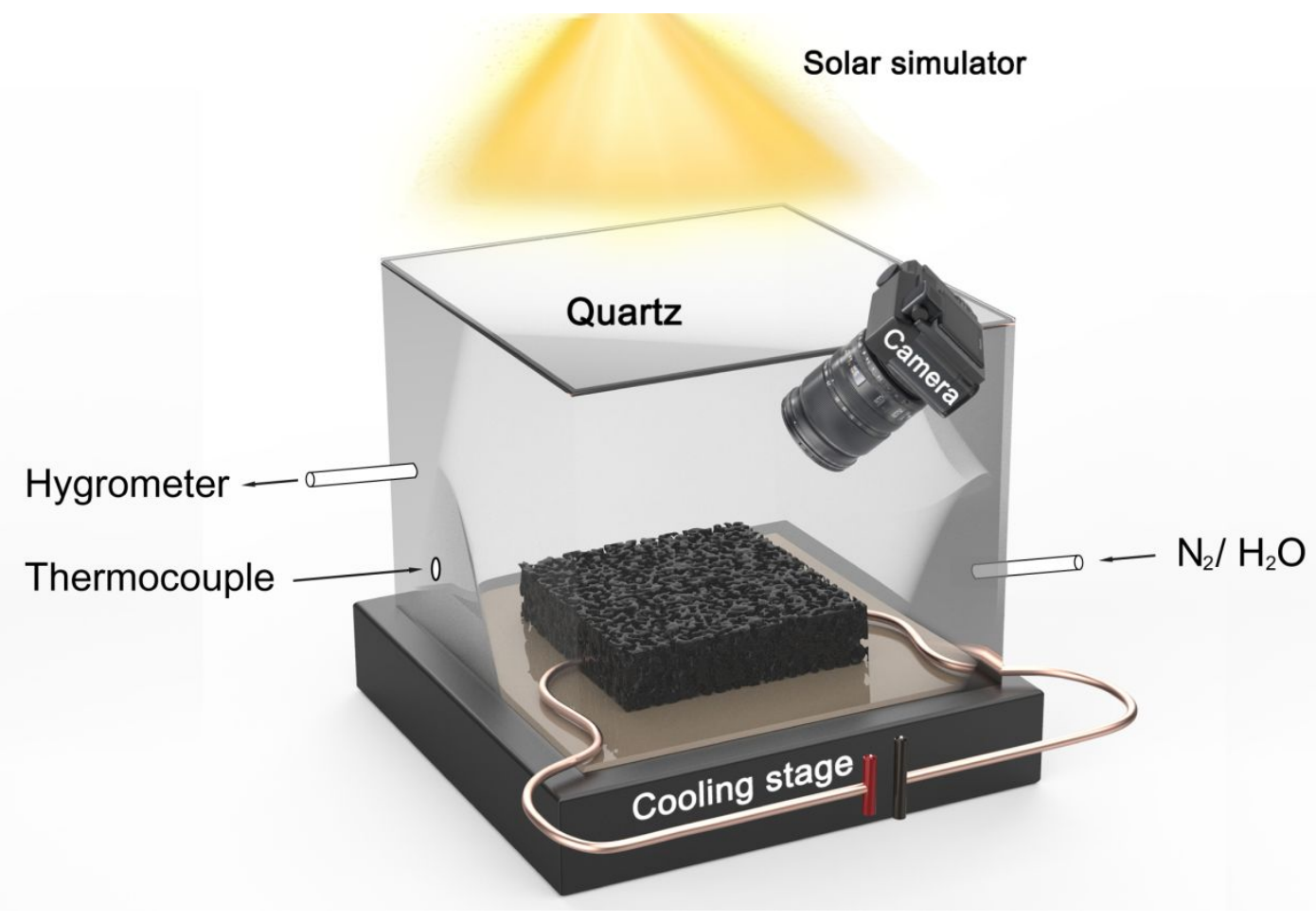

Figure S1. Illustration of simulated solar-electro-thermal anti-icing experiments with controlled solar illumination and voltage. 


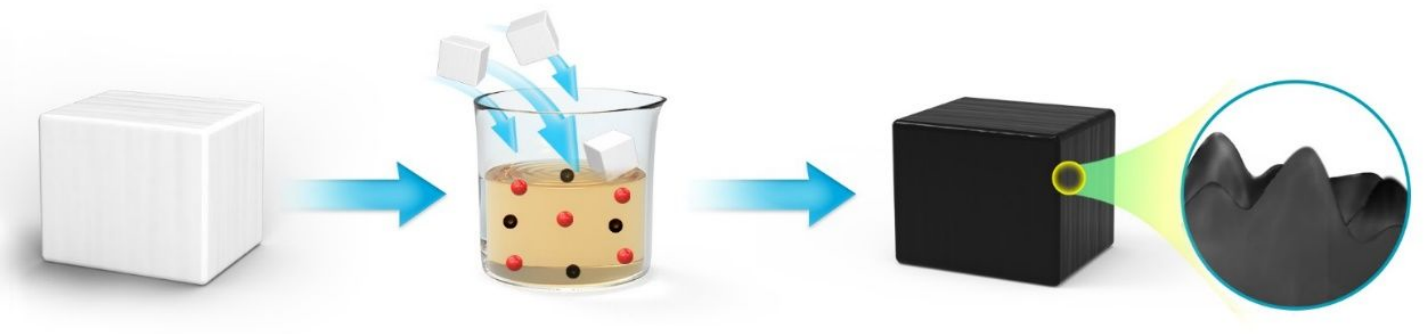

Figure S2. In situ surface wrinkling combined with the self-reinforcing effect leads to stable wrinkles with two-scale wavelengths. 

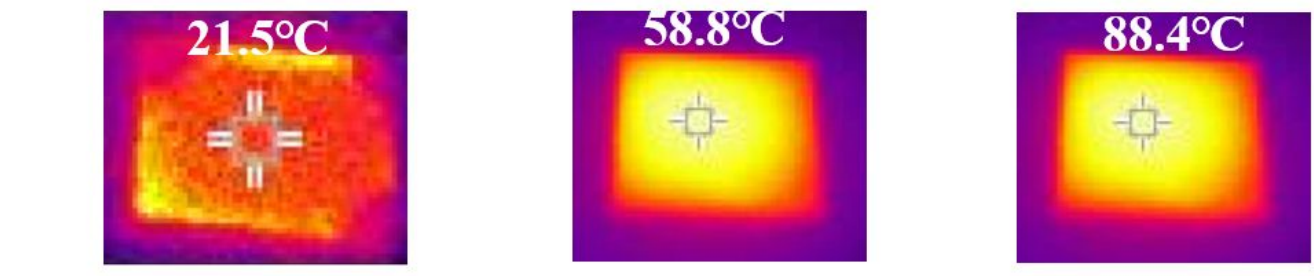

$16.6^{\circ} \mathrm{C}$ $91.2^{\circ} \mathrm{C}$

Figure S3. IR images of POP-P-120 films under $1 \mathrm{~kW} \mathrm{~m}^{-2}$ illumination intensity for $400 \mathrm{~s}$. 
(a)

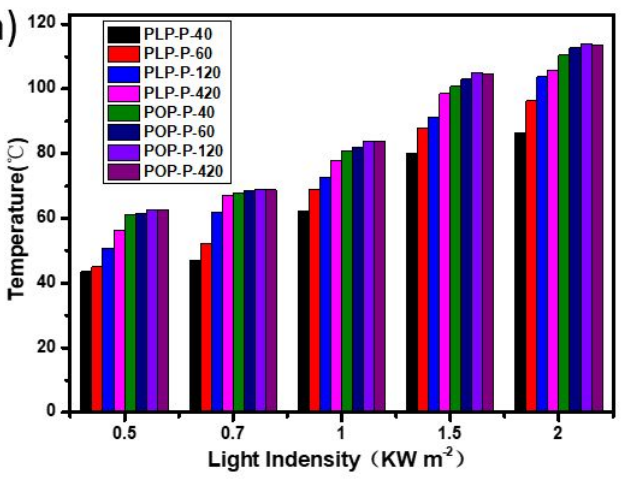

(b) $0.5 \mathrm{KW} \mathrm{m}^{-2} \quad 1 \mathrm{KW} \mathrm{m}^{-2} \quad 1.5 \mathrm{KW} \mathrm{m}^{-2}$

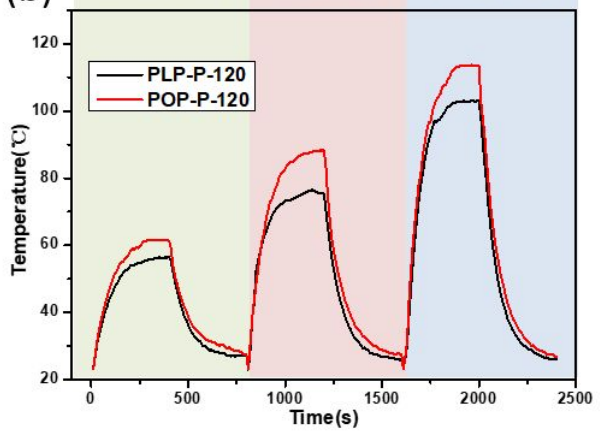

Figure S4. (a) PDMS/PPy films under different light intensity. (b) The temperature changing course of the PLP-P-120 and POP-P-120 under solar illumination of $0.5,1$, and $1.5 \mathrm{~kW} \mathrm{~m}^{-2}$, turned on and off. 


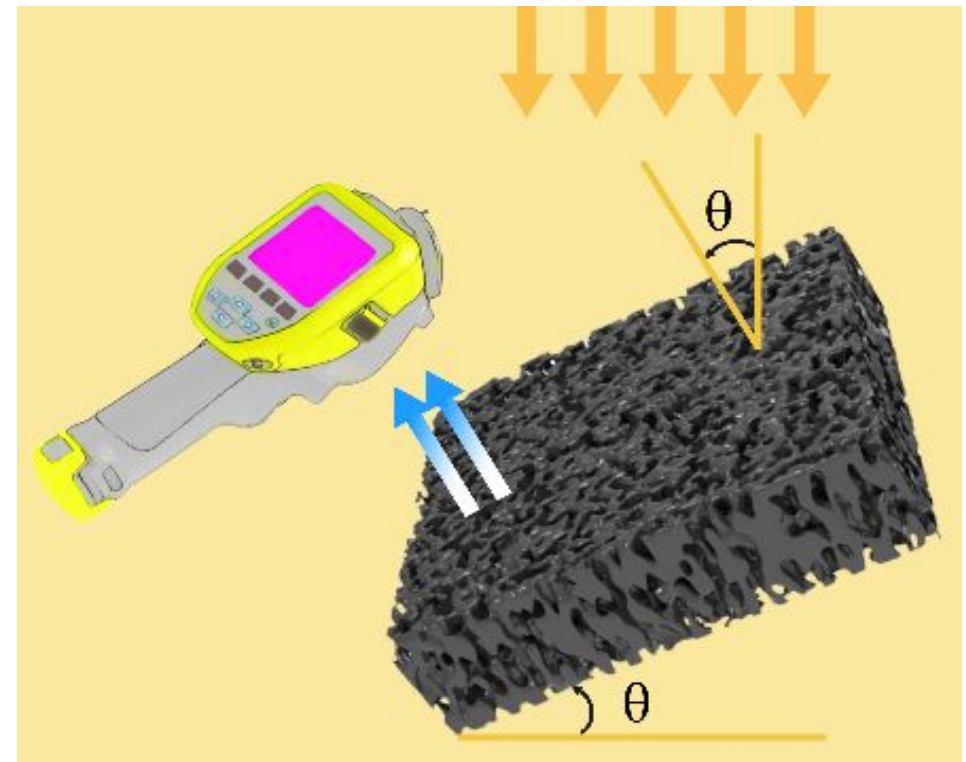

Figure S5. Schematic illustration for photo-thermal conversion measurements at different incident angles. 

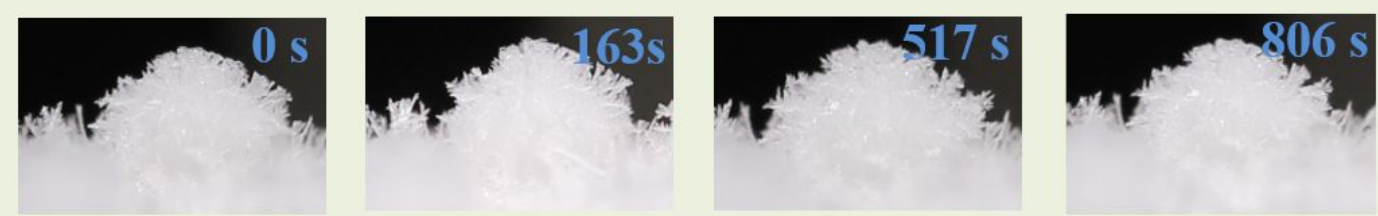

\section{PDMS}

$0 \mathrm{~s}$
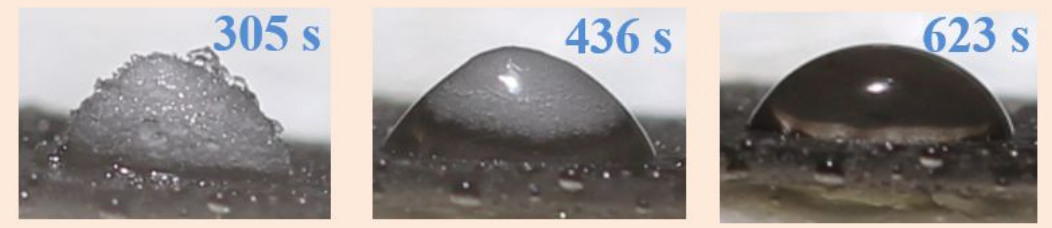

PLP-P-120

Figure S6. In-situ melting process of a frozen droplet (with $40 \mu \mathrm{L}$ volume) on the PDMS and PLP-

P-120 surface under one sun illumination at an ambient temperature of $-40^{\circ} \mathrm{C}$. 


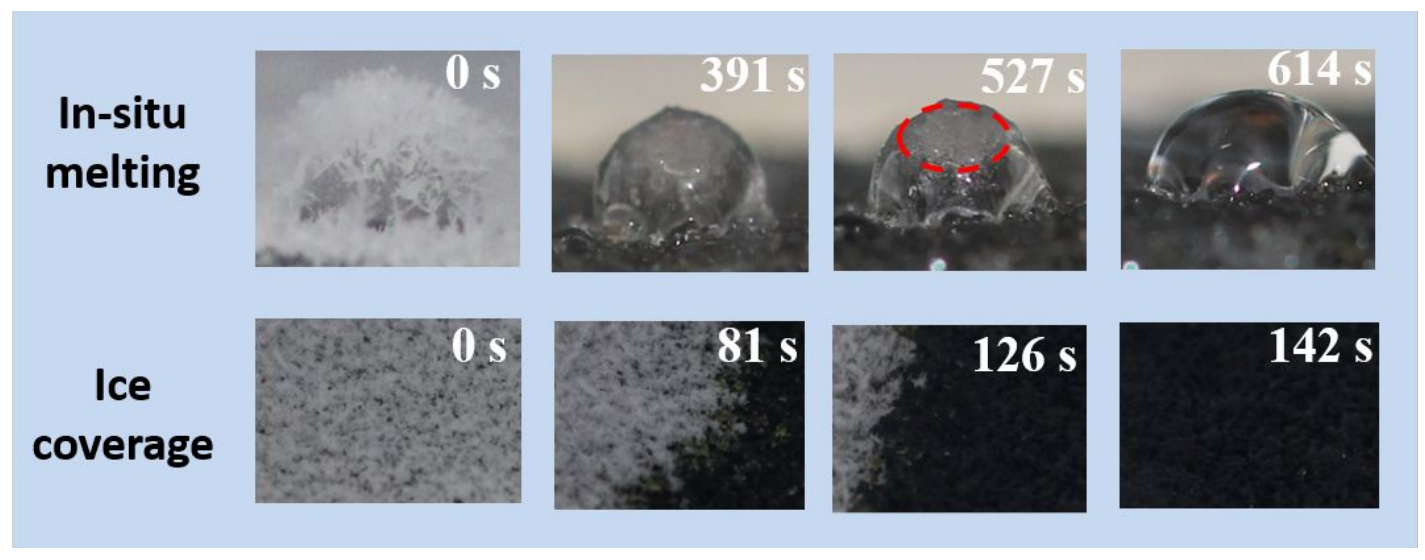

Figure S7. In-situ melting process of a frozen droplet (with $40 \mu \mathrm{L}$ volume) $\left(-40{ }^{\circ} \mathrm{C}\right.$ ) and the ice coverage experiments $\left(-25^{\circ} \mathrm{C}\right)$ on the POP-P-120 surface at the voltage of $32 \mathrm{~V}$. 


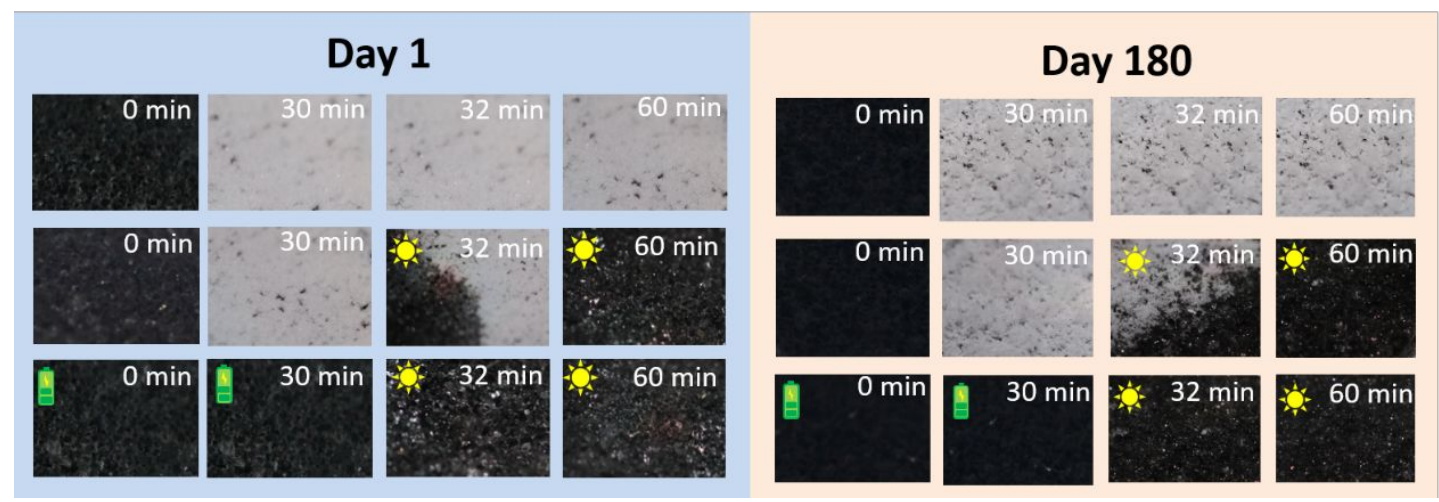

Figure S8. Optical photograph of ice coverage of day 1 and day 180. 

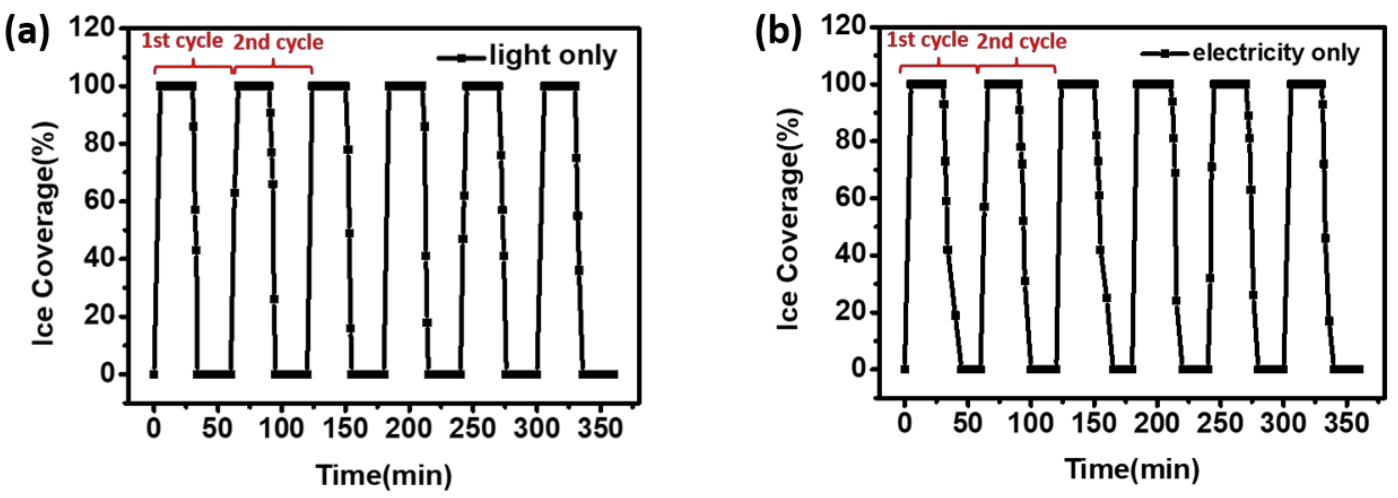

Figure S9. Repeated icing/deicing cycles after 6 cycles (a) under $0.8 \mathrm{~kW} \mathrm{~m}^{-2}$ and (b) at the voltage of $25 \mathrm{~V}$ respectively. 
